\title{
Ortaöğretim Matematik Öğretmen Adaylarının Geogebra Ortamında Materyal Hazırlama Hakkındaki Görüşleri
}

\section{Prospective Secondary Mathematics Teachers' Views on Task Design at Geogebra Environment}

\begin{abstract}
Sema ER*, Yasemin SAĞLAM KAYA**
Öz: Teknolojinin en önemli ürünlerinden biri olan bilgisayarların matematik eğitiminde sunduğu imkânlar, matematik öğretiminde kullanılabilen farklı yazılımların geliştirilmesini sağlamıştır. Bu amaç için geliştirilen yazılımlardan biri de Geogebra'dır. Ücretsiz olması, dinamik özellikleri, yaygın kullanımı, kullanıcı dostu ara yüzü gibi birçok özelliği ile Geogebra bu yazılımlar arasında öne çıkmaktadır. Matematik öğretmenlerinin de dinamik yazılımları aktif olarak kullanıp bu ortamlarda materyal tasarlayarak öğrencilerinin matematiği daha etkili ve kolay öğrenmelerine yardımcı olmaları beklenmektedir. Bu çalışmada Geogebra ortamında hazırlanarak matematik derslerinde kullanılmak üzere geliştirilebilecek materyaller hakkında ortaöğretim matematik öğretmen adaylarının görüşlerini almak ve geleceğe yönelik kullanımları hakkında düşüncelerini ortaya çıkarmak amaçlanmaktadır. Araştırmanın katılımcılarını 2 erkek 9 kadın toplam 11 ortaöğretim matematik öğretmen adayı oluşturmaktadır. Çalışma kapsamında öğretmen adaylarına lisans programları haricinde, beş haftalık bir öğretim deneyi uygulanmıştır. Öğretim deneyinin temel amacı öğretmen adaylarının Geogebra ortamı için teknolojik pedagojik alan bilgilerini eşitlemektir. Öğretim deneyi sonrasında katılımcılar arasından gönüllü olan yedi tanesi ile yarı yapılandırılmış görüşmeler yapılmıştır. Görüşme kayıtları ve öğretim deneyi sırasında oluşturulan gözlemci notları içerik analizi kullanılarak analiz edilmiştir. Araştırmadan elde edilen verilerin analizi sonucunda oluşturulan kodlar üç tema altında toplanmıştır: Geogebra ortamında materyal hazırlamanın avantajları ve dezavantajları, Geogebra ortamında hazırlanan materyallerin kavramsal anlamaya ve motivasyona etkisi ve Geogebra ortamında materyal hazırlamaya uygun konular ve sinıf ortamında kullanımı.
\end{abstract}

Anahtar Kelimeler: Geogebra, materyal, matematik öğretimi, ortaöğretim matematik öğretmen adayları

\begin{abstract}
Computers which are the one of the most important products of technology have led the development of different software which is used for teaching mathematics. Geogebra stands out with many features among those software such as being free of charge, dynamic properties, widespread use, and user friendly interface. Mathematics teachers are expected to use dynamic software actively and design materials on them to help students for learning mathematics easily and effectively. In this study, it is aimed to reveal the views of prospective secondary school mathematics teachers about materials design in Geogebra environment to use in mathematics classes and thoughts about future usage of these materials. The participants of the study consisted of two male and nine female prospective secondary school mathematics teachers. Apart from their degree programs, five-week teaching experiment was conducted with participants of the study. Main goal of teaching experiment is to make prospective teachers' technologic pedagogic content knowledge equal in Geogebra environment. After the teaching experiment semi-constructed interviews were conducted with seven volunteers of the participants. Transcripts of interviews and observation notes, which were taken during the teaching experiment, were analyzed by using content analysis. According to the findings of the study, codes were grouped under three themes: The advantages and disadvantages of preparing materials in Geogebra environment, the effects of materials prepared in Geogebra environment on conceptual understanding and motivation, and appropriate topics of mathematics for preparing materials in Geogebra environment and future usage of materials in classroom environment.
\end{abstract}

Keywords: Geogebra, material, teaching mathematics, prospective secondary mathematics teachers

\footnotetext{
*Doktora Öğrencisi, Hacettepe Üniversitesi, Eğitim Fakültesi, Ankara-Türkiye, e-posta: semaer@hacettepe.edu.tr **Yrd. Doç. Dr., Hacettepe Üniversitesi, Eğitim Fakültesi, Ankara-Türkiye, e-posta: yaseminsaglam@gmail.com
} 


\section{Giriş}

Teknolojinin uygun ve yerinde kullanımı matematiğin derinlemesine anlaşılmasını sağlayarak üst düzey matematik becerilerini geliştirdiği bilinmektedir (Zbiek ve Hollebrands, 2008; National Council of Teachers of Mathematics, 2000). Teknolojinin en önemli ürünlerinden biri olan bilgisayarların matematik eğitiminde uygun yaklaşımlarla kullanıldığında, öğretmeyi ve öğrenmeyi olumlu yönde etkilediği çeşitli araştırmalarda vurgulanmaktadır (Baki, 2000). Ülkemizde de eğitimde teknoloji kullanımına ilişkin yatırımlar sürekli artmakta, okullar teknolojik araçlarla zenginleştirilmekte ve öğrencilerin yeni teknolojilerle tanışma firsatı yakalaması için ortamlar hazırlanmaktadır (Önal ve Çakır, 2016). Özellikle bilgisayar teknolojisinin sunduğu imkânlar, matematik öğretiminde kullanılabilen farklı yazılımların geliştirilmesini sağlamıştır. Bu bağlamda dinamik matematik yazılımları matematiği soyuttan somuta taşıyarak öğrencilerin hayal güçlerini artırmaya yardımcı olan önemli bir araçtır (Hazzan ve Goldenberg, 1997; Güven ve Karataş, 2005). Bu amaç için geliştirilen yazılımlardan biri de Geogebra'dır. Geometri, cebir ve hesaplama işlevlerini bir araya getiren Geogebra, ortaokuldan üniversite düzeyine kadar matematiğin öğrenilmesi ve öğretilmesi sürecinde yaygın olarak kullanılabilen, oldukça kolay kullanıcı ara yüzüne sahip ücretsiz bir dinamik matematik yazılımıdır (Hohenwarter ve Preiner, 2007). Geogebra, birçok dile çevrilmiş hali ve hem öğretmenler hem de öğrenciler için kullanımının kolay ve erişilebilir olmasıyla matematiği öğretmeye ve öğrenmeye teşvik etmektedir (Kutluca ve Zengin, 2011). Ayrıca, Geogebra ortamında hazırlanmış materyaller internet üzerinden paylaşılabilmektedir. $\mathrm{Bu}$ paylaşımlar sayesinde Geogebra, öğretmenlere öğretme ortamı, öğrencilere ise öğrenme ortamı yaratmak için firsatlar sunmaktadır (Dikovic, 2009a; 2009b; Hohenwarter, Hohenwarter, Kreis ve Lavicza, 2008).

Öğrenciler, matematiği durgun ve kavramlarla sınırlı, ezberlenen soyut bir ders olarak görmemeli aksine, matematiksel işlemler ve kavramları birbiriyle ilişkilendirmeli ve çıkarımlarda bulunmalıdır (Stein, Grover ve Henningsen, 1996). Öğrencilerin matematiksel kavramları anlaması ve birbirleriyle ilişkiler kurması için materyaller hazırlanmalı ve bu materyallerin öğrenme ortamına dâhil edilmesine fırsat verilmelidir. Birçok matematik eğitimcisi tarafindan, matematik materyali hazırlamanın öğretim sürecinde önemli bir yer tuttuğu belirtilmektedir (Henningsen ve Stein, 1997; Zbiek ve Hollebrands, 2008; Dikovic, 2009a). Matematiksel materyallerin tasarlanması ve öğrenme ortamında uygulanmas1, ögrencilerin matematiksel düşünme ve çıkarımlar yapma becerilerini artırmaktadır (Simon ve Tzur, 2004). Bilgisayar ortamında hazırlanan matematik materyalleri dinamik olduğu için hem öğrencilerin dikkatini çekmekte hem de matematiği kavramsal olarak daha kolay ve iyi anlamalarına ve konular arasında ilişki kurmalarına yardımcı olmaktadır (Baki, 2000; Berger, 2011). Bu dinamik materyaller, öğrencilerin ezberden uzaklaşıp matematiği keşfederek öğrenmesine olanak sağlamaktadır (Kutluca ve Birgin, 2007). Geogebra ortamı da şekillerin, cisimlerin, doğruların, grafiklerin sürgü seçeneği ile değişimini gösteren, gerektiğinde canlandırma seçeneği ile hareket etmesini sağlayarak matematik materyalleri hazırlamaya uygun bir ortamdır (Hohenwarter ve Fuchs, 2004). Bu dinamik özelliklerinin olmas1, öğrencilerin yaparak, keşfederek öğrenmelerini teşvik eder (Dikovic, 2009a). Geogebra üzerine yapılmış birçok araştırmada, matematik konularının öğrenilmesi ve öğretilmesinin diğer yöntemlere göre daha etkili olduğu bulunmuştur. Kepçeoğlu ve Yavuz (2016) çalışmalarında, trigonometrik fonksiyonların Geogebra ortamında daha iyi öğrenildiği sonucuna ulaşmışlardır. Baltacı, Yıldız ve Kösa (2015), analitik geometri kavramlarını öğrenmede, Geogebra'nın aktif öğrenme ortamı ile kolaylık sağladığını ifade etmişlerdir. Delice ve Karaaslan (2015) ise çalışmalarında, Geogebra'nın görsel boyutu yanında, süreç odaklı kavramsal anlamayı sağladığını da ortaya koymuştur. Aynı zamanda bu çalışmada, öğretmenlerin çalışma öncesinde Geogebra gibi dinamik matematik ve geometri yazılımlarını sadece şekil çizip görselleştirme yapmak için kullanılan araçlar olarak gördüklerini ancak çalışmadan sonra bu kanının, görselliğin yanı sıra sürece uygulanabilen, matematiği öğretmeye ve öğrenmeye aktif olarak katkı sağlayan araçlar olarak değiştiği belirtilmiştir (Delice ve Karaaslan, 2015). Berger (2012), Geogebra kullanarak oluşturulan matematiksel materyallerin öğrenciler tarafından başarılı bir 
şekilde yorumlandığını ve verilen fonksiyonların çeşitli yönlerinin keşfedilmesini sağladığını vurgulamıştır. Ayrıca, matematiksel materyallerin matematik öğretmeni yetiştirme konusunda da etkili olduğu ve öğretmen adaylarına matematiksel materyallerin önemli olduğu ve matematiğin anlaşılmasını, keşfedilmesini sağlaması açısından öğretmenlik yaparken kullanmalarının tavsiye edildiği araştırmalar mevcuttur (Zaslavsky ve Sullivan, 2011).

Alanyazındaki çalışmalara genel olarak bakıldığında matematiksel materyallerin, Geogebra ve diğer dinamik matematik ve geometri yazılımlarının, matematik öğretimine ve öğrenimine olumlu yönde katkı sağladığ 1 ve bu alanda önemli bir yere sahip olduğu görülmektedir (İpek ve Akkuş-İspir, 2011; Zengin ve Kutluca, 2011). Bu bağlamda matematik ögretmenleri de dinamik yazılımları aktif olarak kullanıp bu ortamlarda materyal tasarlayarak öğrencilerinin matematiği daha etkili ve kolay öğrenmelerine yardımcı olmaları beklenmektedir. Ancak öğretmen adaylarının Geogebra ortamında materyal hazırlama konusunda düşüncelerini ortaya çıkaran çok fazla araştırma olmadığı görülmüştür. Matematik öğretmen adaylarının dinamik materyalleri kullanabilmesi ve bu materyaller hakkındaki görüşleri, gelecekte öğrencileri için hazırlayacakları öğrenme ortamları ve öğrencilerine matematiği somutlaştırarak anlatma potansiyellerini ortaya çıkarması açısından önemlidir.

Öğretmen adaylarının bu kapsamda görüsslerini etkileyen önemli unsurlardan biri onların teknolojik pedagojik alan bilgileridir (TPAB). Geleceğin öğretmenleri olan öğretmen adayları sadece teknolojiyi kullanmaları değil öğretim faaliyetlerine de uygun şekilde entegre etmeleri gerekmektedir. TPAB bu bağlamda, teknolojiden yararlanarak kavramların gösterimlerinin, konuyu öğretmek için teknolojilerin yapıcı bir şekilde kullanılmasını sağlayan pedagojik tekniklerin, konuyu zor veya kolay öğrenilir yapan durumların bilgisinin anlaşılmasını ve öğrencilerin karşılaştığı bazı problemlerin düzenlenmesine teknolojinin nasıl yardım edebileceği, öğrencilerin önceki bilgisi ve epistemolojik teoriler bilgisini, teknolojilerin var olan bilgiler üzerine yeni bilgiler inşa edilmesinde nasıl kullanılabileceği bilgisini ve yeni epistemolojiler oluşturmayı veya eskilerini güçlendirmeyi gerektirir (Mishra ve Koehler, 2006). Dolayısıyla herhangi bir ögretim teknolojisini kullanabiliyor olmak tek başına yeterli olmamakta, bu teknolojiyi öğretimsel amaçlar doğrultusunda kullanma konusunda bilgi sahibi olunması gerekmektedir.

$\mathrm{Bu}$ nedenle bu çalışmada Geogebra ortamında hazırlanarak matematik derslerinde kullanılmak üzere geliştirilebilecek materyaller hakkında ortaöğretim matematik öğretmen adaylarının görüşlerini almak ve geleceğe yönelik kullanımları hakkında düşüncelerini ortaya çıkarmak amaçlanmıştır. Bu çalışmada dinamik matematik yazılımı olarak Geogebra'nın tercih edilmesinin en önemli nedeni ücretsiz bir yazılım olmasıdır. Bunun yanı sıra cebir, geometri ve grafik pencerelerinin bir arada olması ve cebirsel ifadelerle geometrik şekillerin ve grafiklerin ilişkisini daha iyi temsil etmesi (Hohenwarter ve Hohenwarter, 2011), matematik ve geometrideki hemen her konuda materyal hazırlamaya uygun olmasıdır. $\mathrm{Bu}$ çalışma kapsamında kullanılan materyal kavramı, matematik konularına yönelik matematiksel düşünceyi ortaya çıkarmayı ve çıkarımlarda bulunmayı sağlayabilecek, konuyu kavramaya firsat veren bir görev (task) olarak tanımlanabilir. Ayrıca bu çalışmada kullanılan görevler oluşturulurken, Brousseau (1998) tarafindan ortaya konan Didaktik Durumlar Teorisi'ndeki (DDT) görevlerin özelliklerini sağlamasına dikkat edilmiştir. DDT'ne göre öğrenme birey ve çevresi tarafından sağlanan iletişim ve dönütler sayesinde gerçekleşir ve elde edilen bilginin anlamlılığı, uygun strateji geliştirebilmesi için öğrenene, öğrenme ortamında sağlanan serbestlik ve belirsizlik ile gerçekleşir (Mackrell, Maschietto ve Soury-Lavergne, 2013). Bu çalışmanın katılımcıları olan öğretmen adayları da hem çalışmaya katılan diğer öğretmen adayları hem de çalıştıkları Geogebra ortamı ve araştırmacılar ile iletişimde bulunup dönütler almışlardır. Bunlara ek olarak çalışma kapsamında kullanılan görevler,

* Öğrenme durumları içermekte

* Öğretmen adaylarını matematiksel problemlerle karşı karşıya getirmekte,

* Öğretmen adaylarının somut ve kavramsal faaliyetlerine dayanmakta,

* Brousseau (1998) tarafından belirtilen didaktik durum aşamalarını içermektedir (Mackrell, Maschietto ve Soury-Lavergne, 2013). 


\section{Yöntem}

\section{Veri toplama süreci ve katılımcılar}

Araştırmada, nitel araştırma yöntemlerinden biri olan durum çalışmasından yararlanılmıştır. Araştırmanın katılımcılarını Ankara'da bulunan bir devlet üniversitesinde öğrenim gören ikisi erkek, dokuzu kadın olmak üzere 11 ortaöğretim matematik öğretmen adayı oluşturmaktadır. Öğretmen adayları lisans programlarında önceki dönemlerde dinamik matematik yazılımlarını da içeren dersler almışlardır. Buna ek olarak öğretmen adaylarına, lisans programları haricinde, beş haftalık bir öğretim deneyi uygulanmıştır. Uygulamalar, bilgisayarlarda, Geogebra yazılımı bulunan bilgisayar laboratuvarında gerçekleşmiştir. Öğretim deneyi kapsamında gerçekleştirilen uygulamaların amacı, öğretmen adaylarının Geogebra ortamında öğretim materyali tasarlama konusunda farkındalıklarını arttırmaktır. Uygulamalar gerçekleştirilirken göz önünde bulundurulan temel prensip, öğretmen adaylarının Geogebra ortamındaki çalışma yeterliliklerini eşitlemek ve teknolojik pedagojik alan bilgilerini bu bağlamda artırmaktır. Her ne kadar öğretmen adayları Geogebra yazılımıyla ve başka dinamik matematik yazımlarıyla daha önce karşılaşmış olsalar da bu ortamda çalışma deneyimlerine bağlı olarak farklı kullanım becerilerine sahip olabilirler ve bu durum görüşlerini etkileme potansiyeline sahip olabilir. $\mathrm{Bu}$ varsayımdan yola çıkarak öğretim deneyiyle öğretmen adaylarının araştırmanın amacına yönelik görüşlerini ortaya çıkarırken daha nitelikli veri elde etmek hedeflenmiştir.

İlk hafta, Geogebra programı tanıtılıp kullanımına ilişkin bilgiler verilmiş ve öğretmen adaylarının deneyerek kullanmalarına firsat verilmiştir.

İkinci hafta, ortaöğretim matematik programında yer alan konulardan parabol konusu üzerine bir materyal hazırlanması planlanmıştır. Parabol denklemi, grafiğini oluşturma, parabolün geometrik tanımı ve belirli integral ile grafik altında kalan bölgenin alanını bulma işlemleri Geogebra ortamında materyal hazırlayarak öğretmen adaylarının kullanmalarına ve keşfetmelerine firsat verilmiştir. Materyal hazırlama aşamasında öğretmen adaylarına gerektiğinde destek verilmiştir. Şekil-1 de parabol ve belirli integral ile ilgili materyal örneği verilmiştir.

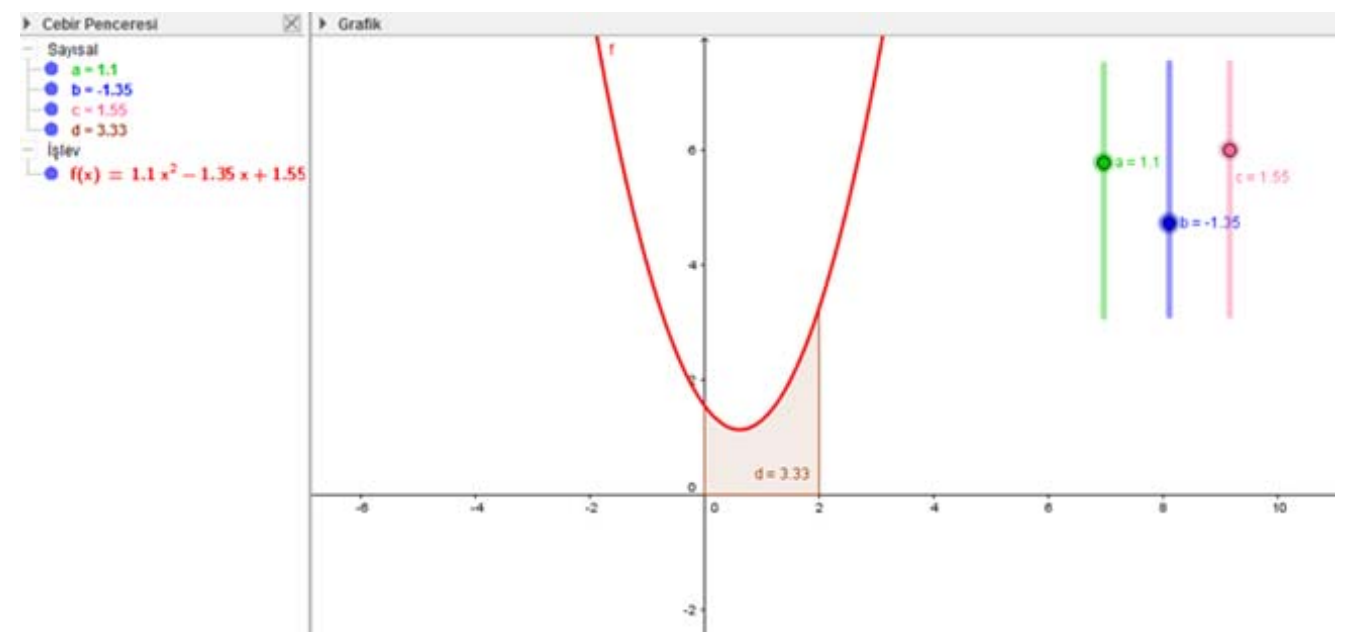


Şekil 1. Parabol- Belirli Integral

Üçüncü hafta, hiperbol konusu seçilerek hiperbol denklemi ve grafiği oluşturma ile ilgili materyal tasarımı planlanmıştır. Öğretmen adayları ile birlikte hiperbol grafiği oluşturmak için gerekli bilgiler araştırılıp adım adım hiperbol grafiği oluşturulup değişiklikler için sürgüler kullanılmış ve sürgüler sayesinde hiperbol denklemindeki sabitler değiştiğinde grafikteki değişim gözlenmiştir. Şekil-2 de hiperbol ile ilgili yapılan materyallerden bir örnek verilmiştir.

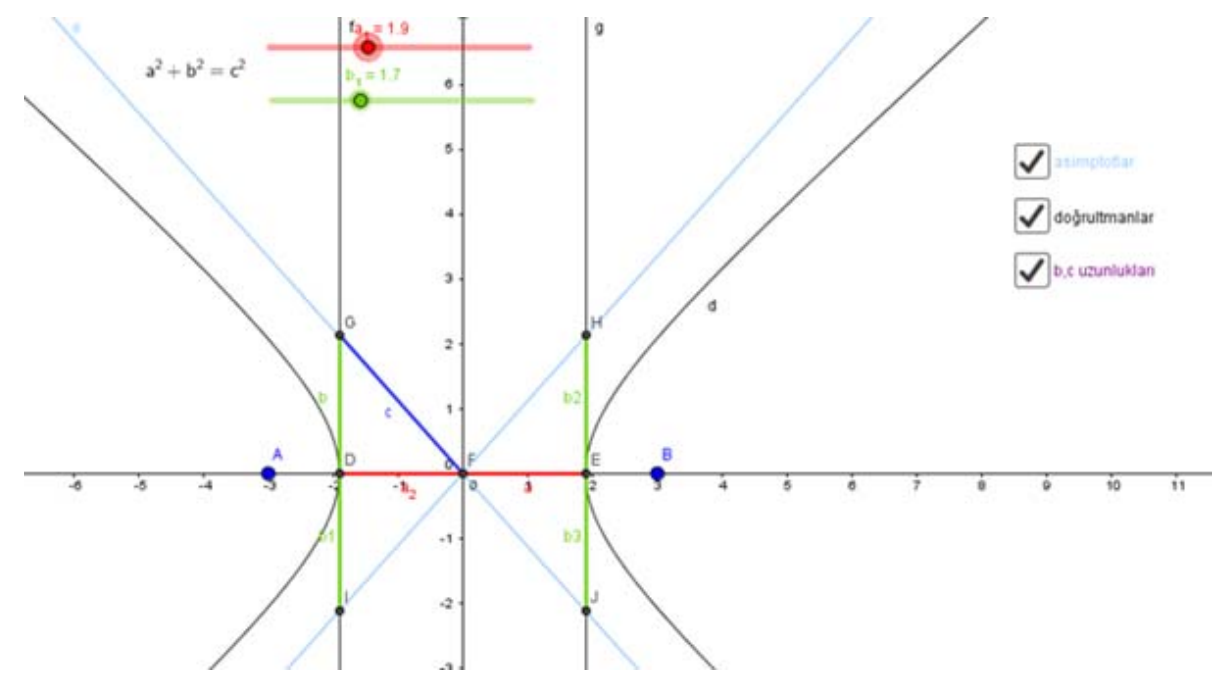

Şekil 2. Hiperbol

Dördüncü hafta, Pisagor teoremi seçilmiştir. Farklı ispat yöntemleri olan bu teorem ile ilgili bir ispat materyali hazırlanması planlanmıştır. Öğretmen adaylarıyla beyin fırtınası yapılarak farklı yöntemler üzerinde tartışılmıştır. Karenin alanından yararlanılarak bir ispat materyali hazırlanıp dik üçgenin kenar uzunlarıyla alanlar arasındaki ilişkiyi keşfetme amaçlanmıştır. Alan yöntemini kullanarak Pisagor teoremi ispatıyla ilgili materyal Şekil-3 te verilmiştir. 


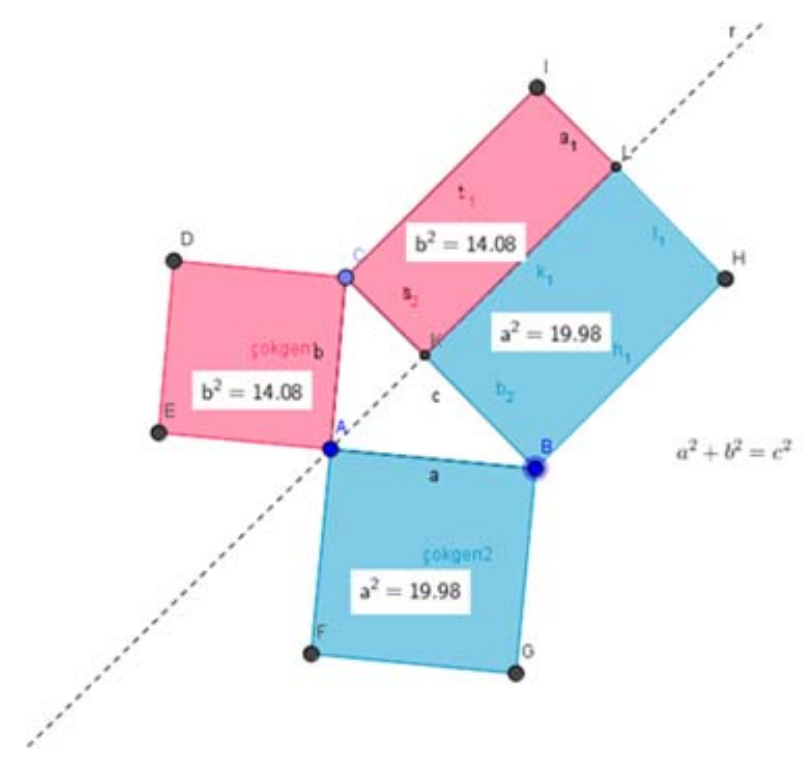

Şekil 3. Pisagor Teoremi

Beşinci hafta, öğretmen adaylarına istedikleri bir konu seçerek onunla ilgili materyal hazırlamaları istenmiştir. Öğretmen adayları bireysel veya grup olarak çalışıp materyaller tasarlanmışlardır. Şekil-4 te hazırlanan materyallerden bir örnek verilmiştir. 

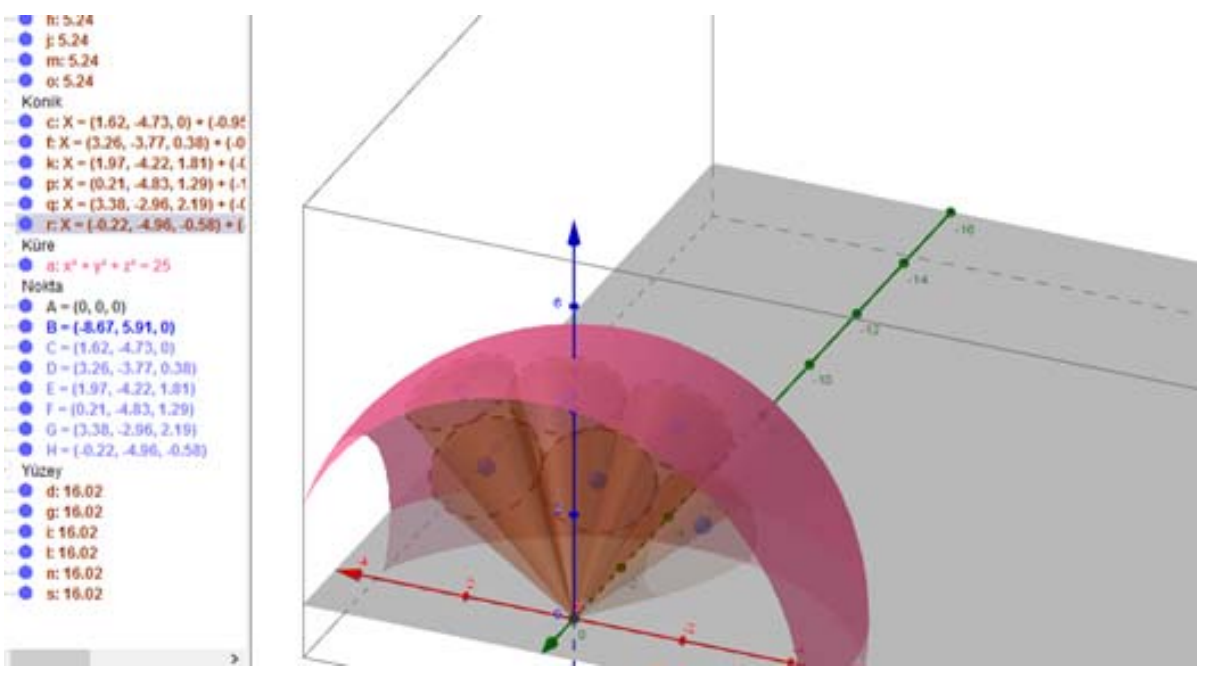

Şekil 4. Kürenin Yüzey Alanı Ve Hacmi

Materyallerin tasarım aşamasında, bu materyalleri öğretmen olduklarında kendi sınıflarında nasıl kullanılabilecekleri, öğretim sırasında oluşturabilecek ek materyallerin neler olabileceği, öğretime hangi boyutlarda katkı sağlayabileceği konusunda görüşleri sorulmuş ve gözlemci notu olarak kaydedilmiştir.

Şekillerde gösterilen her bir materyal bilgisayar laboratuvarında öğretmen adaylarıyla birlikte aşama aşama yapılmış ve materyaller üzerine tartışmalar gerçekleștirilmiștir. Araştırmacılar da öğretim deneyi sırasında materyalleri yaparak öğretmen adaylarına projeksiyon cihazı yardımıyla yansıtmış ve her bir aşamayı ayrıntılı olarak göstermiştir. Öğretmen adayları materyal üzerine çalışırken araştırmacı onları gözlemleyerek gerektiğinde yardımcı olmuştur.

Ayrıca Geogebratube web sitesinde yayınlanmış materyaller incelenmiştir. Bunun yanında öğretim deneyi sırasında öğretmen adayları gözlemlenmiş ve gözlemci notları oluşturulmuştur. Beş haftalık programın sonunda öğretim deneyine katılanlar arasından görüşme için gönüllü olan yedi ortaöğretim matematik öğretmen adayı ile yarı yapılandırılmış görüşmeler yapılmıştır. Görüşmelerde katılımcıların izni alınarak ses kaydı alınmıştır. Yarı yapılandırılmış görüşmeler belirli düzeyde standartlık ve bununla birlikte esneklik sağlaması ve eğitim araştırmalarına uygun bir teknik olması nedeniyle tercih edilmiştir (Türnüklü, 2000; Yıldırım ve Şimşek, 2008).

\section{Verilerin analizi}

Çalışmanın verilerini iki kaynaktan elde edilmiştir: Katılımcılarla yapılan görüşme kayıtları ve araştırmacıların oluşturdukları gözlem verileri. Öncelikle görüşme kayıtları yazılı metne çevrilmiş ve gözlem raporları ile birlikte düzenlenmiştir. Veri analiz yöntemi olarak içerik analizi kullanılmıştır. Bu yöntemin asıl amacı elde edilen verileri açıklayabilecek kavramlara ve ilişkilere ulaşmaktır (Yıldırım ve Şimşek, 2008). Bu süreçte elde edilen veriler ilk olarak kavramsallaştırılır, daha sonra ortaya çıkan bu kavramlar uygun bir şekilde düzenlenir ve 
açıklayıcı temalar oluşturulur. Bu bağlamda nitel araştırma verileri dört aşamadan geçilerek raporlaştırılır (Yıldırım ve Şimşek, 2008):

1. Verileri Kodlama

2. Temaları oluşturma

3. Kodları temalar altında düzenleme

4. Bulgular ve Yorumlama

Araştırmanın güvenirliğini sağlamak amacıyla kodlayıcılar arası güvenirliğe bakılmıştır. Neuendorf'a (2002) göre kodlayıc1lar arası güvenirliğe bakarken kodların \%10-50'sinin güvenirlik analizine alınması yeterlidir. $\mathrm{Bu}$ nedenle görüşme kayıtlarının 1/7'i başka bir araştırmacı tarafından kodlanarak kodlama karşılaştırılması yapılmıştır. Karşılaştırma, uyum oranı formülü ile hesaplanmıştır (Miles ve Huberman, 1994).

$\mathrm{P}=\mathrm{Na} /(\mathrm{Na}+\mathrm{Nd}), \mathrm{P}$ : Uyum oranı, Na: Görüş birliği, Nd: Görüş ayrılığı

$\mathrm{Bu}$ formüle göre uyuşum yüzdesi yüzde 0,76 olarak hesaplanmıştır. Miles ve Huberman'a (1994) göre uyum yüzdesinin en az yüzde 0,70 olması güvenirliği sağladığını göstermektedir. Bu bağlamda bu araştırma için hesaplanan değerin kabul edilebilir olduğu görülmektedir. Analiz sürecinde katılımcıların gerçek isimleri kullanılmamış, bunun yerine K1K7 şeklinde bir kodlama yapılmıştır.

\section{Bulgular}

Araştırmadan elde edilen verilerin analizi sonucunda oluşturulan kodlar üç tema altında toplanmıştır: Geogebra ortamında materyal hazırlamanın avantajları ve dezavantajları, Geogebra ortamında hazırlanan materyallerin kavramsal anlamaya ve motivasyona etkisi ve Geogebra ortamında materyal hazırlamaya uygun konular ve sınıf ortamında kullanımı.

\section{Geogebra ortaminda materyal hazırlamanin avantajlart ve dezavantajlart}

Görüşmeler sonucu elde edilen verilerde Geogebra ortamının, hazırlanan materyallere renk, hareket ve boyut katmasıyla öğrenmeyi somutlaştırdığı belirtilmiştir. Böylece akılda kalıcılığının da arttığı ve öğrencilerin daha çok ilgisini çekebileceği de görüşler arasında yer almaktadır. Aynı zamanda işlenen dersi tek düzelikten kurtaracağ 1 ve eğlenceli hale getireceği belirtilmiştir. Ortaöğretim matematik öğretmen adaylarından K2, K3 ve K5 şu şekilde söz etmiştir:

Görsel açıdan çok zengin ve ögrencilerin ilgisini çekebilecek düzeyde. K2

Geogebra'da etkinlik hazırladığınız da daha kalıcı bir öğrenmis oluyor ve dersi tek düzelikten ve sikıcılıktan kurtarmış oluyorsunuz. K3

Bir şeyi ögrenirken görsel olarak gördügü̈mde çok daha fazla akılda kalıcı oluyor.

Daha ĕglenceli oluyor. K5

$\mathrm{Bu}$ ifadeler incelendiğinde Geogebra'nın görsel açıdan zengin olması matematik dersi açısından avantajlı bir durum oluşturduğu düşünülmektedir.

Geogebra'nın menüsünde hazır şekillerin bulunmasının çizim kolaylığı sağladığı belirtilmiştir. Sürgü özelliği ve canlandırma ile materyallerin üzerinde yapılan değişimin fark edilmesine firsat vermesi, öğretmen adaylarının dikkatini çektiği yapılan gözlemlerle ortaya çıkmıştır. Ayrıca bu durum görüşmelerde de ifade edilmiştir. K1, K3, K4 ve K6 şu şekilde bahsetmiştir:

Canlandırma yapıyoruz daha dikkat çekiyor. K1

Sürgüleri değiştirdikçe değişimi görebiliyorsun... Kullanımı zor değil gayet rahat bir şekilde her şey oluşturabiliyoruz. Çok geniş bir kullanımı var. K3

El becerimizle işte birazcık da olsa bilgimizle yukarıda her şeyin (menü) net olmastyla halledebiliriz. $K 4$

Sürgü özelliği görsel açıdan çok güzeldi. K6 
Geogebra'nın dilinin Türkçe olmasının da kullanımda kolaylıklar sağladığı görüşler arasında yer almıştır. Bu durumu K2 şu şekilde dile getirmiştir:

Dili Türkçe hani daha etkili oluyor... Daha rahat hemen çabuk çabuk bir şeyler yapabiliriz. $K 2$

Bunların yanı sıra Geogebra'yı daha önce öğrendikleri bir matematik yazılımıyla kıyasladıklarında daha kolay ve kullanışlı olduğu, ezberlemeyi gerektiren kodların olmadığı ve menüsünde hazır şekillerin olması Geogebra'yı daha avantajlı hale getirdiği ifade edilmiştir. K4 ve $\mathrm{K} 5$ bu durumu aşağıdaki gibi ifade etmişlerdir.

Geogebra biraz daha kullanışlı. Komut gerçekten sıkıntı... Burada zaten toolbar da her şey var istediğimiz şeyleri orda bulabiliyoruz. Bir de geometri olduğu için rahat kullanabiliyoruz. Denklemini bilmesek bile parabol, hiperbol çizebiliyoruz. K4

Çok uğraş gerekmiyor. Belli şeylerin nasıl yapıldiğını bilmek ve sadece düşünüp bunu kullanmak önemli oluyor. Çok ezber gerektiren ve çok fazla program bilmeyi gerektiren şeyler değil. K5

Veriler incelendiğinde Geogebra'nın çok fazla dezavantajı olmadığı görülmüştür. Öne sürülen dezavantajlar, her ögrencinin tek tek yapması durumunda sürenin yeterli olamayacağı, okullardaki fiziksel koşulların sağlanamayabileceği, öğrencilerin ilgisinin olmayabileceği ve yaratıc1lı ve emek gerektiği şeklindedir. Bu konuda K1, K2, K3, K4 ve K5'in ifadeleri aşağıdaki gibidir.

Sifirdan bir şey üretmek istersek zor diye düşünüyorum. Emek istiyor. K1

Zaman konusunda sıkıntı çekilebilir her öğrenciye bu denettirilirse. Zaman konusunda daha geniş olmall zaman ama ders saatleri buna uygun olmayabilir. Her okulda uygulanamayabilir. Olanakları konusunda. K2

Belki bilgisayar kullanmaya çok yatkin olmayan ögrencilerin ya da bunla çok haşır neşir olmayanların anlamasında bazı güçlükler çıkartabilir. Sınıfin fiziksel özelliklerinden kaynaklanabilir. K3

Ben pek dezavantaj görmüyorum. Çok mantıklı bir program. K4

Emek verici uğraştırıcı. Dezavantaj olabilir ama onun dlşında dezavantaj görmüyorum. K5

Yukarıdaki ifadeler incelendiğinde Geogebra ortamında materyal hazırlamanın dezavantajları avantajlarına göre daha az olduğu ve Geogebra'nın olumlu bir izlenim bıraktığ söylenebilir. Tablo 1'de avantaj ve dezavantajlar özetlenmiştir.

Tablo 1. Geogebra Ortaminda Materyal Hazırlamanin Avantaj ve Dezavantajlart

\begin{tabular}{lll}
\hline $\begin{array}{l}\text { Geogebra'nın } \\
\text { özellikleri }\end{array}$ & Sağladığı kolaylıklar & $\begin{array}{l}\text { Geogebra ortamında } \\
\text { materyal hazırlamanın } \\
\text { Avantajı x Dezavantaji }\end{array}$ \\
\hline -Renk & -İlgi çekicilik & \\
-Boyut & -Kalıcılık & Avantaj \\
-Hazır şekiller & -Eğlenceli & \\
-Sürgü & - Kolaylık & \\
-Hareket & -Farkındalık & \\
& -Tek düzelikten kurtarma & \\
\hline & Sinıf ortamında oluşturduğu \\
& gereklilikler & \\
\hline
\end{tabular}




\begin{tabular}{ll}
\hline & -Yaratıcılık \\
-Süre & Dezavantaj \\
-Fiziksel koşullar & \\
-İlgi & \\
\hline
\end{tabular}

\section{Geogebra ortaminda hazırlanan materyallerin kavramsal anlamaya ve motivasyona etkisi}

Matematik soyut konular içerdiği için Geogebra ortamında hazırlanan materyallerin somutlaştırılması, renklendirilmesi ve şekillere hareket kazandırılması kavramların daha anlaşılır hale gelmesini sağladığı gözlem ve görüşmelerle ortaya çıkarılmıştır. Görüşmelerdeki söylemlere göre Geogebra'da materyal hazırlandığında kavramlar arası ilişkilerin daha iyi görüldüğü ve kalıcı bir öğrenmenin gerçekleştiği belirtilmiştir. K1, K2 ve K3 kavramsal anlama ile ilgili görüşlerini aşağıdaki gibi ifade etmişlerdir:

Kavramlar arasındaki ilişskiyi daha iyi anlayabilirler görerek. Sözel anlattı̆̆ımızda bu kadar etkili olmuyor ama gördüklerinde o ilişkiyi daha iyi kurabilirler. KI

Kavramları daha somutlaştırır belki. Neyin nerden geldiğini gördü̆̈̈̈ için daha soyuttan somuta geçiş olabilir. K2

Göstererek hatta uygulama yaparak kendileri oluşturmaları çok daha kalıcı ve temeli sağlam öğrenme sağlayabilir. K3

Geogebra ortamında hazırlanan materyallerin öğretmen adaylarının dikkatini çektiği ve ileriki meslek hayatlarında Geogebra'da materyal hazırlayıp kullanma adına motivasyonlarını arttırdığı gözlemlenmiş ve görüşmeler sonucunda da kendileri de ifade etmişlerdir. Örneğin, K1 ve $\mathrm{K} 2$ şöyle bahsetmişlerdir:

Bilgisayar hakkında önyargılarım vardl. Genelde istediğimi yapamam, Açılmaz bir aksilik olur. Ama Geogebra ile baya bir şeyler yaptım. Beni olumlu etkiledi. Illeride de kullanabileceğimi düşünüyorum. Hatta yaptığım etkinlikleri aldım. K1

Ben ilerde öğretmen olduğumda Geogebra'yı kullanmak isterim, kullanırım da. Daha güzel bir program... Çabuk çabuk her şeyi yapabiliyoruz. K2

Öğretmen adayları, ayrıca, Geogebra ortamında hazırlanan materyallerin öğrencilerin de motivasyonunu olumlu yönde arttırabileceğini, matematiğe karşı tutumlarını olumlu yönde etkileyeceğini ve matematiği sevdirebileceğini belirtmişlerdir. K2, K3 ve K5 şöyle ifade etmişlerdir:

Motivasyonunu arttırır. Güdüyü arttırır. Matematiğe karşı tutumu da fazlalaştırır. Programın güzelliği görselliği açısından öğrencinin ilgisini çekiyor ve matematiğe daha merakla yaklaşmasını sağlayabilir. K2

Böyle bir programı kullaniyor olabilmek, kendilerinin görüyor olması ve tahtada düz bir anlatım yapılmıyor olmasi hem motivasyonunu artıracaktır hem de soyut kalmayacak çok olumlu yönde etkileyecektir. K3

Istediğim şekilde değiş̧irebiliyorum, renklendiriyorum. İstediğim her şeyi oluşturuyorum orda. Ë̆lenceliydi ve matematik sevdirilebilir. K5

Geogebra ile çalışırken katılımcılardan üç kişi grupla, iki kişi bireysel ve iki kişi de hem grup hem bireysel çalışmanın duruma göre tercih edilebileceğini belirtmişlerdir. Ayrıca öğretmen adayları görüş̧melerde de grup olarak çalışmanın daha avantajlı olduğunu, grup çalışmalarında fikir alışverişi yaptıklarını ifade etmişlerdir. Bireysel çalışmanın da yararlı olduğu bazı katılımcılar tarafından vurgulanmıştır. Görüşmelerde bu durum K1, K2, K3, K6 ve K7 tarafından aşağıdaki gibi ifade edilmiştir. 
Tabi ki birlikte her zaman birileriyle ya da çevreyle ögrenmeye birileri daha katıldığında artıyor bence... Benim göremediğim bir şeyleri başkaları görebilir. K1 Bir şeyleri yazmak çizmek gerekli bence. Bireysel daha etkili... K2

Birebir kendini görüp her şeyi kendiniz yaptığınızda hem çok daha eğlenceli oluyor hem sizin bir ürününüz oluyor. $K 3$

Bireysel olarak kendi ilgimiz bazında istediğimiz şeyi yapabiliriz. Grupça da projeyi beraber yapabiliriz. Öyle bir şey varsa işbirliği içinde olabilir. Yardımlaşarak yapabiliriz. $K 6$

Grup olarak beyin firtınasl yapılır, her zaman daha uygun. K7

Tablo 2'de Geogebra ortamında hazırlanan materyallerin kavramsal anlamaya ve motivasyona etkisi özetlenmiştir.

Tablo 2. Geogebra Ortamindaki Materyallerin Kavramsal Anlamaya ve Motivasyona Etkisi

\begin{tabular}{lll}
\hline Geogebra'nın özellikleri & Sağladığı kolaylıklar & $\begin{array}{l}\text { Kavramsal Anlamaya ve } \\
\text { Motivasyona Etkisi }\end{array}$ \\
\hline -Renklendirme & -Görsellik & \\
-Hareket & -Ürün oluşturma & -Motivasyonu Artırma \\
-Değişikliğe izin verme & $\begin{array}{l}\text {-̇̇lişkilerin gözlenmesi } \\
\text {-Aktif katılım }\end{array}$ & -Kavramsal Anlamayı Artırma \\
\hline & -Grup Çalışması & -Kavramsal Anlamayı Artırma \\
\hline
\end{tabular}

"Göreve ve bireysel tercihe bağlı olarak

\section{Geogebra ortamında materyal hazırlamaya uygun konular ve sınıf ortamında kullanımı}

Öğretmen adayları Geogebra ortamında materyal hazırlamaya birçok matematik konusunun uygun olduğunu belirtseler de geometri konularını, özellikle 3 boyutlu cisimleri anlatmada daha kullanışlı olduğunu belirtmişlerdir. Katılımcıların ifadeleri aşağıdaki gibidir:

Ben geometri konularının daha uygun olduğunu düşünüyorum. Aslında Türev ve Integral ile ilgili uygulamalar da yaptık ama daha çok geometride 2 boyutlu geometride ve 3 boyutlu şekiller uygun diye düşünüyorum. K1

Geometri açısından daha uygun gibi. Çünkü daha görsel, daha anlatılabilir ve ilgi çekici olabilir. Renkler şekiller olsun. K2

Özellikle 3 boyutlu şeyleri göstermede,...Pisagor ispatında. Bu tür ispat gerektiren ya da birebir çocukların eline veremeyeceğimiz şeylerde çok daha etkilidir. K3

Geometrik ispatlar özellikle. Integral olabilir. Alan, hacim, döndürme vardı. Başka cisimlerin alanları vardı. Basit geometrik şeylerde de kullanılabilir. K4

Paraboller, elipsler olabilir... Geometri kısmı ben çok eğlendiğim için belki ondandır. Integral olabilir. Cebir kısmı da kullanışlı olabilir diye düşünüyorum. K5

3 boyutlu küre silindir açılımları, katı cisimlerle ilgili onların anlatımında bence çok güzel kullanılabilir, analitik geometri. K6

Parabol, elips, 3 boyutlu cisimler, analitik geometri gibi onun konularl. Bence geogebra şekil çizmek için önemli... K7

Katılımcıların ifadeleri incelendiğinde geometri konularının Geogebra ortamında materyal oluşturmaya uygun konular olduğu belirtilmiştir. Tablo-3 te bu konular özetlenmiştir.

Tablo 3. Geogebra Ortaminda Materyal Hazırlamaya Uygun Konular

\begin{tabular}{lll}
\hline Geogebranın özellikleri & Sağladı̆̆ı kolaylıklar & Kullanılabilecek konular \\
\hline - 2 ve 3 Boyutlu gösterim & -Görsellik & -Geometri \\
-Alan & -İspat & -Cebir \\
\hline
\end{tabular}


-Hacim

-Analitik Geometri

-Döndürme

-Geometrik şekiller

-Cebir

Ayrica Geogebra ortamında hazırlanan materyallerin sinıf ortamında uygulamasının öğrenciler ve öğretmenler açısından öğrenmeyi ve öğretmeyi olumlu yönde etkileyeceği öğretmen adayları tarafindan ifade edilmiştir. K1, K2, K4 ve K7'nin bu bulguya yönelik ifadeleri aşağıdaki gibidir:

Örneğin, bir prizmanın açılımını tahtaya çizmek zorken orda (Geogebrada) açıp gösterebilirim. Derste işi kolaylaştırtyor. K1

Sinıf ortamında buluş yöntemleri olarak da güzel bir yöntem bence. K2

Anlatıma yardımcı olur. Görsel destekli olduğu için akılda kalıcı olur. Bir yandan anlatırken bir yandan göstermek gayet kullanışlı olur. $K 4$

(Sinıf içinde) kullanırım. Dediğim gibi öğrenci daha rahat anlasın daha net görsün daha görsel olsun diye. Çünkü çok askıda kallyor. Biz öğrendiğimizde askıda kalmıştı. Daha rahat ögrenirler diye düşünüyorum görsel olduğu için. K7

\section{Tartışma ve sonuç}

$\mathrm{Bu}$ çalışmada ortaöğretim matematik öğretmen adaylarının Geogebra ortamında hazırlanan materyaller ile ilgili farklı açılardan görüşleri ve ileriki meslek hayatlarında kullanımı konusunda motivasyonları incelenmiştir. Veriler incelendiğinde önceki araştırmalarla paralel sonuçlar elde edilmiştir. Kutluca ve Zengin (2011) ve Berger (2011) Geogebra yazılımının görselliği artırmasıyla öğrencilerin matematiksel kavramlar arasındaki ilişkileri daha iyi anlayacağını ve zorlandıkları konuları da daha iyi kavrayacaklarını ifade ederek benzer sonuçlara ulaşmışlardır. Bunun yanı sıra bu araştırmanın sonuçları, Hohenwarter ve Jones (2007) ve Diković'in (2009a; 2009b) Geogebra'nın kullanışlı bir öğretimsel yazılım olduğu sonucuyla benzerlik göstermektedir. Bu çalışmada da öğretmen adayları, Geogebra ortamında materyal hazırlamanın kolay olduğunu ifade etmişlerdir. Farklı yazılımlarda komut ezberleme ve bu komutları hatırlama gerekliyken, Geogebra'nın menüsünün kullanım kolaylığına değinmişlerdir.

Delice ve Karaaslan (2015) Geogebra gibi dinamik ortamlarda hazırlanan materyallerin sürece uygulanabilen, matematiği öğretmeye ve öğrenmeye aktif katılım sağladığı sonucu da bu çalışmanın sonuçlarıyla benzerlik göstermektedir. Öğretmen adayları. materyaller hazırlanırken ilişkilerin daha iyi görüldüğünü, bunun da kavramsal anlamaya katkı sağlayacağını belirtmişlerdir. Ayrıca Hohenwarter ve Fuchs (2004) Geogebra ortamının, şekillerin, cisimlerin, doğruların sürgü seçeneği ile değişimini gösterdiği, gerektiğinde canlandırma seçeneği ile hareket etmesini sağladığı için matematik materyalleri hazırlamaya uygun olduğunu belirtmişlerdir. Bu sonuç da bu çalışmada elde edilen verilerden çıkan, materyal hazırlarken Geogebra ortamının sağladığı kolaylıklar sonucunu doğrular niteliktedir. Bunun yanında Baltacı, Yıldız ve Kösa (2015) çalışmalarında, analitik geometri kavramlarını öğrenmede Geogebra'nın aktif öğrenme ortamı ile kolaylık sağladığına yönelik elde ettikleri sonuç, analitik geometri konusunun Geogebra ortamında materyal hazırlamaya uygun bir konu olarak görülmesiyle örtüşmektedir.

Çalışmanın katılımcılarından bazıları Geogebra ortamında hazırlanacak materyallerin yaratıcılık gerektirmesi ve daha fazla çabaya ihtiyaç duymasını bir dezavantaj olarak belirtmişlerdir. DDT'nde (Brousseau, 1998) belirtildiği gibi Geogebra ortamında materyal kullanımı birey ve çevrenin (bu çalışma bağlamında teknoloji yani Geogebra, diğer öğretmen adayları ve araştırmacı) etkileşimini gerektirir. Araştırmanın oluşturulduğu bağlam bu etkileşimi desteklemiş ve öğretimsel hedefler gözetildiği için öğretmen adayları, matematiksel anlamda öğretim problemleri oluşturma durumlarına yönlendirilmiştir. Bu durum öğretmen adaylarında, Geogebra veya dinamik ortamlar ile deneyimlerine bağlı olarak farklı düzeyde bilişsel yük ve 
çabaya neden olmuştur. Dolayısıyla bu ortamda algılanan dezavantajlar bireysel farklılıklara göre değişiklik gösterebilmektedir.

Çalışmanın bulguları incelendiğinde Geogebra yazılımının dilinin Türkçe olması, kolay ulaşılabilir ve kullanışlı olması, renklendirme ve hareketlendirme özellikleriyle Geogebra ile hazırlanan materyallerin sinıf ortamında kullanımı öğretmen adayları tarafindan uygun bulunmuştur. Bu sonuç Hohenwarter, Hohenwarter, Kreis ve Lavicza'nın (2008) çalışmalarında ortaya çıkan ve analiz dersine yönelik materyaller hazırlayarak yapılan öğretimde, Geogebra'nın öğrenmeyi desteklediği sonucuyla benzerlik göstermektedir. Öğretmen adayları, gelecekteki meslek hayatlarında uygun koşullar sağlandığı takdirde, Geogebra'yı kullanarak materyaller hazırlayıp matematik öğretimini eğlenceli ve akılda kalıcı bir şekilde yapmayı düşünmektedirler.

Çalışmadan elde edilen bulgular incelendiğinde öğretmen adaylarının çoğunlukla Geogebra'nın görsel anlamda sağladığı katkılar ve dikkat çekici özelliklerine vurgu yaptıkları gözlenmiştir. $\mathrm{Bu}$ özellikler Geogebra'nın önemli özellikleri arasında olsa da öğretimsel özellikleri de öğretmen adayları için aynı öneme sahip olmalıdır. Ancak çalışmada kullanılan materyallerin öğretmen adayları tarafindan matematiksel anlamda bilindik olması, öğretici rolünden ziyade katılımcı rolünde karşılaşmış olmaları böyle düşünmelerine neden olmuş olabilir. Öğretmen adaylarının stajlarında bu tür yazılımları kullanmalarına yönelik oluşturulacak içerikler öğretmen adaylarının görüşlerinin değişmesine neden olabilir.

$\mathrm{Bu}$ çalışmanın sonuçlarına göre üniversitelerin matematik öğretmenliği lisans programlarında, dinamik matematik yazılımı ortamlarında materyal hazırlamaya olanak sağlayan derslerin sayısının arttırılması öğretmen eğitimi açısından faydalı olacaktır. Bu sayede öğretmen adayları dinamik geometri ve matematik yazılımlarını kullanma becerilerini kazanarak verdikleri derslerin içeriğinin zenginleştirebilecek ve bu konuda daha fazla yeterlilik kazanabileceklerdir. Ayrıca bu derslerde, öğretmen adaylarına bu tür yazılımları kullanmanın bir gereklilik olduğu şeklinde duyuşsal özellikler kazanmalarına özen gösterilmelidir. $\mathrm{Bu}$ şekilde yetişen öğretmenlerin meslek yaşantılarında öğrencilerine etkili bir matematik öğretimi gerçekleştirme ve kendilerini geliştirme firsatı sağlanmış olur.

Sadece ortaöğretim değil, ilköğretim matematik öğretmenliği lisans programlarında da verilen derslerin içeriği zenginleştirilebilir. Milli Eğitim Bakanlığı'na bağlı özel ve devlet okullarında görev yapan matematik öğretmenlerine Geogebra ve materyal tasarlama ile ilgili hizmet içi eğitimler verilebilir. Diğer taraftan okullarda uygun bilgisayar laboratuvarları oluşturulup öğrencilerin Geogebra programıyla çalışmaları ve materyaller hazırlamaları teşvik edilebilir.

Gelecek araştırmalarda, Geogebra ortamında hazırlanmış materyallerle okullarda öğrencilerle deneyler yapılabilir. Ayrıca öğretmen adaylarının mezun olup öğretmenliğe başladıklarında Geogebra ortamında materyal hazırlayıp hazırlamadıkları, kullanıp kullanmadıkları incelenebilir.

\section{Kaynaklar}

Baki, A. (2000). Bilgisayar donanımlı ortamda matematik öğrenme. Hacettepe Üniversitesi Ĕ̈itim Fakültesi Dergisi, 19(19), 186-193.

Baltacı, S., Yıldız, A. ve Kösa, T. (2015). Analitik geometri öğretiminde geogebra yazılımının potansiyeli: öğretmen adaylarının görüşleri. Turkish Journal of Computer and Mathematics Education, 6(3), 483-505.

Berger, M. (2011). A framework for examining characteristics of computer-based mathematical tasks, African Journal of Research in Mathematics, Science and Technology Education, $15(2), 3-15$.

Berger, M.(2012). One computer-based mathematical task, different activities. Proceedings of the 36th Conference of the International Group for the Psychology of Mathematics Education, 2, 59-66. Taipei, Taiwan: PME.

Brousseau, G. (1998). Theory of didactical situations in mathematics, Springer. 
Delice, A. ve Karaaslan, G. (2015). Dinamik geometri yazılımı etkinliklerinin öğrenci performansları bağlamında incelenmesi: analitik düzlemde doğru denklemleri. Eğitim Bilimleri Dergisi, 41(41), 35-57.

Diković, L. (2009a). Applications GeoGebra into teaching some topics of mathematics at the college level. Computer Science and Information Systems, 6(2), 191-203.

Diković, L. (2009b). Implementing dynamic mathematics resources with GeoGebra at the college level. International Journal of Emerging Technologies in Learning (IJET), 4(3).

Güven, B. ve Karataş, İ. (2005). Dinamik geometri yazılımı Cabri ile oluşturmacı öğrenme ortamı tasarımı: Bir model. Illkögretim Online, 4(1), 62-72.

Hazzan O., \& Goldenberg E.P.(1997). Students' understanding of the notion of function in dynamic geometry environments, International Journal of Computers for Mathematical Learning, 1, 263-291.

Henningsen, M., \& Stein, M.K. (1997). Mathematical tasks and student cognition: Classroombased factors that support and inhibit high-level mathematical thinking and reasoning. Journal for Research in Mathematics Education, 28(5), 524-549.

Hohenwarter, M., \& Fuchs, K. (2004). Combination of dynamic geometry, algebra and calculus in the software system GeoGebra. In: Proceedings of Computer Algebra Systems and Dynamic Geometry Systems in Mathematics Teaching Conference.

Hohenwarter, M. and Jones, K. (2007). Ways of linking geometry and algebra: the case of Geogebra. Proceedings of the British Society for Research into Learning Mathematics, 27(3), 126-131.

Hohenwarter, M., \& Preiner, J. (2007). Dynamic mathematics with GeoGebra. Journal of Online Mathematics and its Applications, ID 1448, 7.

Hohenwarter, M., Hohenwarter, J., Kreis, Y., \& Lavicza, Z. (2008). Teaching and Learning Calculus with Free Dynamic Mathematics Software GeoGebra. Proceeding of International Conference in Mathematics Education 2008, Monterrey, Mexico.

Hohenwarter, M., \& Hohenwarter, J. (2011). Geogebra resmi kullanım kılavuzu (M. Doğan ve E. Karakırık, Çev.) Ankara: Nobel. (Original work published, 2008).

İpek, S. ve Akkuş-İspir, O. (2011). Preservice Elementary Mathematics Teachers' Geometric and Algebraic Proof Process with Dynamic Geometry Software. Turkish Journal of Computer and Mathematics Education, 2(1), 20-34.

Kepçeoğlu, İ. \& Yavuz, İ. (2016). Teaching a concept with GeoGebra: Periodicity of trigonometric functions. Educational Research and Reviews, 11(3), 573-581.

Kutluca, T. ve Birgin, O. (2007). Doğru denklemi konusunda geliştirilen bilgisayar destekli öğretim materyali hakkında matematik öğretmeni adaylarının görüşlerinin değerlendirilmesi. Gazi Üniversitesi Gazi Ë̆itim Fakültesi Dergisi, 27(2), 81-97.

Kutluca, T. ve Zengin, Y. (2011). Matematik öğretiminde GeoGebra kullanımı hakkında öğrenci görüşlerinin değerlendirilmesi. Dicle Üniversitesi Ziya Gökalp Eğitim Fakültesi Dergisi, 17, 160-172.

Mackrell, K., Maschietto, M., \& Soury-Lavergne, S. (2013). The interaction between task design and technology design in creating tasks with Cabri Elem. Margolinas, C. (Ed.). Task Design in Mathematics Education. Proceedings of ICMI Study 22 (Vol. 1). Oxford

Miles, M.B., \& Huberman, M. (1994). Qualitative Data Analysis: An expanded sourcebook (2th Ed.) Tousand Oaks, CA: Sage

Mishra, P., \& Koehler, M.J. (2006). Technological pedagogical content knowledge: A framework for teacher knowledge. Teachers College Record, 108(6), 1017-1054.

National Council of Teachers of Mathematics. (2000). Principles and standards for school mathematics. Reston, VA: Author.

Neuendorf, K.A. (2002). The content analysis guidebook. Thousand Oaks, CA: Sage.

Önal, N. ve Çakır, H. (2016). Ortaokul matematik öğretmenlerinin matematik öğretiminde bilişim teknolojileri kullanimina ilişkin görüşleri. Mersin Üniversitesi Eğitim Fakültesi Dergisi, 12(1), 76-94. DOI: http://dx.doi.org/10.17860/efd.51865. 
Simon, M.A., \& Tzur, R. (2004). Explicating the role of mathematical tasks in conceptual learning: An elaboration of the hypothetical learning trajectory. Mathematical thinking and learning, 6(2), 91-104.

Stein, M.K., Grover, B.W., \& Henningsen, M. (1996). Building student capacity for mathematical thinking and reasoning: An analysis of mathematical tasks used in reform classrooms. American educational research journal, 33(2), 455-488.

Türnüklü, A. (2000). Eğitimbilim araştırmalarında etkin olarak kullanılabilecek nitel biraraştırma tekniği: Görüşme. Kuram ve Uygulamada Eğitim Yönetimi Dergisi, 6(4), 543-559.

Yıldırım, A. ve Şimşek, H. (2008). Sosyal bilimlerde nitel araştırma yöntemleri. Seçkin Yayınc1l1k, 7.bask1.

Zaslavsky, O., \& Sullivan, P. (Eds.). (2011). Constructing knowledge for teaching secondary mathematics: Tasks to enhance prospective and practicing teacher learning (Vol. 6). Springer Science \& Business Media.

Zbiek, R.M., \& Hollebrands, K. (2008). A research-informed view of the process of incorporating mathematics technology into classroom pracice by in-service and prospective teachers. In M. K. Heid \& G. W. Blume (Eds.), Research on technology and the teaching and learning of mathematics: Research synthesis (Vol. 1, pp. 287344). Charlotte, NC: Information Age.

Zengin, Y. ve Kutluca, T.(2011). Ortaöğretim matematik dersinde geogebra kullanımı üzerine öğretmen adaylarının görüşleri. 5 th International Computer \& Instructional Technologies Symposium, 22-24 September 2011, Firat University, Elazığ- Türkiye.

\section{Extended Abstract}

It is a known fact that appropriate use of technology improves higher order thinking skills and provides deeper understanding of mathematics (Zbiek \& Hollebrands, 2008; National Council of Teachers of Mathematics, 2000). In particular, opportunities of computer technology have led to the development of different software that can be used in teaching mathematics. One of the software developed for this purpose is Geogebra. Geogebra is a free dynamic mathematics software combining geometry, algebra and computing functions, which can be used widely from middle school up to university level for learning and teaching mathematics with quite easy user interface (Hohenwarter \& Preiner, 2007). In many studies it is reported that using Geogebra is more effective than other methods for learning and teaching mathematics. Thus, mathematics teachers are expected to use dynamic software actively and design materials in these environments to help students for learning mathematics easily and effectively. However, it was observed that there aren't so many researches on prospective teachers' views about material design at Geogebra environment. One of the key factors influencing their views in this regard is their technological pedagogical content knowledge (TPCK). Therefore, to be able to use any instructional technology alone is not enough, teachers also have the knowledge how to use these technologies in line with instructional purposes. To this respect, the purpose of this study is to reveal the views of prospective mathematics teachers about tasks, which is developed in Geogebra environment in order to use in mathematics classes and learn their opinion about future usage of this software in their classes. The concept of task used in the study can be defined as a material, which can help students to grasp the mathematical idea, make inferences and understand the mathematical subject. In addition, the tasks used in this study, have the properties of Didactical Situations Theory (DST), which was introduced by Brousseau (1998).

\section{Method}

In the study, case study was used as the research method. The participants of the study consisted of two male and nine female prospective mathematics teachers who are attending a public university in Ankara. Within the scope of the study, a five-week teaching experiment was carried out in computer labs of their university. In each week of teaching experiment a geogebra material was designed step by step with participants and made in-class discussions on materials' 
instractional purposes. The data for the study were obtained from two sources: interviews with the participants and researchers' observations notes during teaching experiments. Obtained data were analyzed by using content analysis. Intercoder reliability was used for the reliability of the analysis.

\section{Findings}

The codes that were obtained from the analysis of the data were grouped under three themes: the effects of materials prepared in Geogebra environment on conceptual understanding and motivation, and appropriate topics of mathematics for preparing materials in Geogebra environment and future usage of materials in classroom environment.

According to interview results, Geogebra environment gives color; dynamism and dimension to the tasks so, mathematical tasks become concrete. Being visually rich of Geogebra, it is considered to provide an advantage in terms of mathematics lessons. It was also noted that Geogebra's tools provides convenience for drawing; and there are not so many disadvantages of Geogebra considered by participants.

Prospective mathematics teachers stated that the tasks in Geogebra might increase the positive motivation and attitudes of students at school towards mathematics. Participants also specified that most of the mathematical topics are appropriate to design tasks in Geogebra environment, moreover in terms of geometry; Geogebra is more useful in showing 3 dimensional objects.

It was observed that the motivation of prospective teachers on task design in Geogebra environment was increased depending on increase in TPCK and they plan to design task in Geogebra environment in their future classes.

\section{Discussion and conclusion}

In this study, it was examined that prospective secondary mathematics teachers' views on task design in Geogebra environment from different perspectives and their motivations for using Geogebra in future professional life. The results of the study were similar to previous researches. In this study, the prospective teachers stated that it was easy to design task in Geogebra environment, while different software may cause to memorize commands and recall them. Moreover, they referred to easy usage of Geogebra menu.

Some of the participants of the study stated that Geogebra environment requires creativity and more efforts as a disadvantage. According to DST (Brousseau, 1998), use of tasks in Geogebra environment requires an interaction between individuals and the milieu (in this context milieu is technology namely Geogebra, other prospective teachers and researchers). Present research environment has supported the creation of this context. Because these interactions and instructional goals for the participants were taken into consideration, prospective teachers were directed to create instructional problems in mathematical sense. This case gives a cause for cognitive load and extra effort on participants depending on their experience with Geogebra or dynamic environments. Thus, the perceived disadvantages may vary in this environment according to individual differences and previous experience.

According to the findings of this study, it was observed that most of prospective teachers emphasized the visual contribution of Geogebra on instructional environment and attention-grabbing features. Even though these features are important for Geogebra, instructional features of Geogebra should also be equally important for prospective teachers. However, the materials used in study are being familiar for prospective teachers in mathematical sense, and the prospective teachers' role in the study is being participants rather than learner may cause them to emphasize those features. Prospective teachers' perceptions can be changing when contents in their educational program are reconstructed for using of this type of software in their school practice. 